\title{
What Should the Optimal Blood Pressure Goal Be in Patients with Diabetes Mellitus?
}

\section{Wilbert S. Aronow}

Department of Medicine, Division of Cardiology, New York Medical College, Valhalla, NY, USA

In the absence of randomized control data, the seventh report of the Joint National Committee on Prevention, Detection, Evaluation, and Treatment of High Blood Pressure recommended that patients with diabetes mellitus should have their blood pressure decreased to less than 130/80 $\mathrm{mm} \mathrm{Hg}$ [1]. In the absence of randomized control data, the American Diabetes Association recommended that patients with diabetes mellitus and hypertension should have their blood pressure decreased to less than $130 / 80 \mathrm{~mm} \mathrm{Hg}$ [2]. In the absence of randomized control data, the American Heart Association 2007 guidelines recommended that patients with diabetes mellitus and hypertension should have their blood pressure decreased to less than 130/80 mm Hg [3]

The 2009 European Society of Hypertension guidelines stated that lowering the blood pressure to less than $130 / 80 \mathrm{~mm} \mathrm{Hg}$ in patients with diabetes mellitus is unsupported by prospective trial data, and that the systolic blood pressure should be reduced to less than $140 \mathrm{~mm} \mathrm{Hg}$ in these patients [4]. The American College of Cardiology Foundation/ American Heart Association 2011 expert consensus document on hypertension in the elderly recommended that the blood pressure should be decreased to less than $140 / 90 \mathrm{~mm} \mathrm{Hg}$ in adults younger than 80 years with diabetes mellitus or chronic kidney disease [5]. On the basis of data from the Hypertension in the Very Elderly trial [6], these guidelines recommended that the systolic blood pressure should be reduced to 140 to $145 \mathrm{~mm} \mathrm{Hg}$ if tolerated in adults aged 80 years and older [5]. I concur with these guidelines $[7,8]$. The following studies discuss the reasons for my recommendations.

An observational subgroup analysis was performed in 6,400 of the 22, 576 patients enrolled in the International Verapamil SR-Trandolapril Study (INVEST) [9]. The study participants had diabetes mellitus and coronary artery disease. Patients were categorized as having tight control of their blood pressure if they could maintain their systolic blood pressure below $130 \mathrm{~mm} \mathrm{Hg}$ and their diastolic blood pressure below $85 \mathrm{~mm} \mathrm{Hg}$, usual control if they could maintain their systolic blood pressure between 130 to $139 \mathrm{~mm} \mathrm{Hg}$, and uncontrolled if their systolic blood pressure was $140 \mathrm{~mm} \mathrm{Hg}$ or higher.

During 16,893 patient-years of follow-up, a cardiovascular event rate of $12.6 \%$ occurred in patients with usual control of blood pressure versus $19.8 \%$ in patients with uncontrolled hypertension, $p<0.001$ [9]. The incidence of cardiovascular events was $12.6 \%$ in patients with usual control of blood pressure versus $12.7 \%$ in patients with tight control of blood pressure ( $\mathrm{p}$ not significant). The all-cause mortality rate was $11.0 \%$ with tight control of blood pressure versus $10.2 \%$ with usual control of blood pressure $(p=0.06)$. When extended follow-up to 5 years following the close of INVEST was included, the all-cause mortality rate was $22.8 \%$ with tight control of blood pressure versus $21.8 \%$ with usual control of blood pressure, $p=0.04$. [9].

The Action to Control Cardiovascular Risk in Diabetes (ACCORD ) blood pressure trial randomized 4,733 patients with type 2 diabetes mellitus to intensive blood pressure control with a target systolic blood pressure of $<120 \mathrm{~mm} \mathrm{Hg}$ or to standard blood pressure control with a target systolic blood pressure $<140 \mathrm{~mm} \mathrm{Hg} \mathrm{[10].} \mathrm{The} \mathrm{primary} \mathrm{com-}$ posite outcome was nonfatal myocardial infarction, nonfatal stroke, or death from cardiovascular causes. Mean follow-up was 4.7 years. After 1 year, the mean systolic blood pressure was $119.3 \mathrm{~mm} \mathrm{Hg}$ in the intensive blood pressure control group versus $133.5 \mathrm{~mm} \mathrm{Hg}$ in the standard blood pressure control group. The annual rate of the primary outcome was $1.87 \%$ in the intensive blood pressure control group versus $2.09 \%$ in the standard blood pressure control group (p not significant) [10]. The annual rate of death from any cause was $1.28 \%$ in the intensive blood pressure control group versus $1.19 \%$ in the standard blood pressure control group ( $\mathrm{p}$ not significant). The annual rate of death from cardiovascular causes was $0.52 \%$ in the intensive blood pressure control group versus $0.49 \%$ in the standard blood pressure control group ( $\mathrm{p}$ not significant). The annual stroke rate was $0.32 \%$ in the intensive blood pressure control group versus $0.53 \%$ in the standard blood pressure control group, $\mathrm{p}=0.01$ (number needed to treat to reduce 1 stroke in 1 year $=476$ patients). Serious adverse events attributed to antihypertensive treatment occurred in $3.3 \%$ of the intensive blood pressure control group versus $1.3 \%$ of the standard blood pressure control group $(\mathrm{p}$ $<0.001)$ [10].

The ONgoing Telmisartan Alone and in combination with Ramipril Global Endpoint Trial (ONTARGET) included 9,603 diabetics, mean age 66.1 years, and 15,981 nondiabetics, mean age 66.6 years, with hypertension at high risk for cardiovascular events [11]. The primary outcome was a composite of cardiovascular death, nonfatal myocardial infarction, nonfatal stroke, or hospitalization for heart failure. Mean follow-up was 4.6 years. Compared with nondiabetics, diabetics had a $48 \%$ significant increase in the primary endpoint, a $56 \%$ significant increase in cardiovascular death, a 30\% significant increase in myocardial infarction, a 39\% significant increase in stroke, and a 206\% significant increase in hospitalization for congestive heart failure [11].

In both diabetics and nondiabetics, antihypertensive drug treatment reduced the primary outcome if the baseline systolic blood pressure was between 143 to $155 \mathrm{~mm} \mathrm{Hg}$ [11]. Except for stroke, there was no benefit in reducing fatal or nonfatal cardiovascular outcomes by reducing the systolic blood pressure below $130 \mathrm{~mm} \mathrm{Hg}$ in diabetics and in nondiabetics. The lowest incidence of death from cardiovascular causes in diabetics occurred with a systolic blood pressure of $135.6 \mathrm{~mm}$

*Corresponding author: Wilbert S. Aronow, MD, Cardiology Division, New York Medical College, Macy Pavilion, Room 138, Valhalla, NY 10595, USA, Tel: (914) 493-5311; Fax: (914) 235-6274; E-mail: wsaronow@aol.com

Received May 28, 2011; Accepted May 31, 2012; Published June 04, 2012

Citation: Aronow WS (2012) What Should the Optimal Blood Pressure Goal Be in Patients with Diabetes Mellitus? J Diabetes Metab 3:e109. doi:10.4172/21556156.1000e109

Copyright: (c) 2012 Aronow WS. This is an open-access article distributed under the terms of the Creative Commons Attribution License, which permits unrestricted use, distribution, and reproduction in any medium, provided the original author and source are credited. 
Citation: Aronow WS (2012) What Should the Optimal Blood Pressure Goal Be in Patients with Diabetes Mellitus? J Diabetes Metab 3:e109. doi:10.4172/2155-6156.1000e109

Hg (range 130.6 to $140.5 \mathrm{~mm} \mathrm{Hg}$ ). The lowest incidence of death from cardiovascular causes in nondiabetics occurred with a systolic blood pressure of $133.1 \mathrm{~mm} \mathrm{Hg}$ (range 128.8 to $137.4 \mathrm{~mm} \mathrm{Hg}$ ). For the primary outcome, the highest risk in both diabetics and in nondiabetics occurred in patients with the lowest or highest in-trial diastolic blood pressure (67.2 and $86.7 \mathrm{~mm} \mathrm{Hg}$, respectively) [11].

The mean systolic blood pressure was $144 \mathrm{~mm} \mathrm{Hg}$ in both the intensively treated diabetics in the United Kingdom Prospective Diabetes Study [12] and in the post hoc subgroup analysis of the Hypertension Optimal Treatment trial [13]. The mean systolic blood pressure was 135 $\mathrm{mm} \mathrm{Hg}$ in the intensively treated diabetics in the Action in Diabetes and Vascular Disease: Preterax and Diamicron Modified Release Controlled Evaluation (ADVANCE study) [14]. Therefore, the mean systolic blood pressure was not reduced to less than $130 \mathrm{~mm} \mathrm{Hg}$ by intensive blood pressure treatment in these 3 studies.

On the basis of the available data, the blood pressure in patients with hypertension at high risk for cardiovascular events because of diabetes mellitus should be reduced to less than $140 / 90 \mathrm{~mm} \mathrm{Hg}$ in patients younger than 80 years and the systolic blood pressure reduced to 140 to $145 \mathrm{~mm} \mathrm{hg}$ if tolerated in patients aged 80 years and older $[5,7,8]$.

\section{References}

1. Chobanian AV, Bakris GL, Black HR, Cushman WC, Green LA, et al. (2003) The Seventh Report of the Joint National Committee on Prevention, Detection, Evaluation, and Treatment of High Blood Pressure. The JNC 7 report. JAMA 289: 2560-2572.

2. American Diabetes Association (2003) Standards of medical care for patients with diabetes mellitus. Diabetes Care 26: S33-S50.

3. Rosendorff C, Black HR, Cannon CP, Gersh BJ, Gore J, et al. (2007) Treatment of hypertension in the prevention and management of ischemic heart disease. A scientific statement from the American Heart Association Council for High Blood Pressure Research and the Councils on Clinical Cardiology and Epidemiology and Prevention. Circulation 115: 2761-2788.

4. Mancia G, Laurent S, Agabiti-Rosei E, Ambrosioni E, Burnier M, et al. (2009) Reappraisal of European guidelines on hypertension management: a European Society of Hypertension Task Force document. Blood Press 18: 308-347.
5. Aronow WS, Fleg JL, Pepine CJ, Artinian NT, Bakris G, et al. (2011) ACCF/AHA 2011 expert consensus document on hypertension in the elderly: a report of the American College of Cardiology Foundation Task Force on Clinical Expert Consensus Documents developed in collaboration with the American Academy of Neurology, American Geriatrics Society, American Society for Preventive Cardiology, American Society of Hypertension, American Society of Nephrology Association of Black Cardiologists, and European Society of Hypertension. J Am Coll Cardiol 57: 2037-2114.

6. Beckett NS, Peters R, Fletcher AE, Staessen JA, Liu L, et al. (2008) Treatment of hypertension in patients 80 years of age or older. $\mathrm{N}$ Engl $\mathrm{J}$ Med 358: 1887-1898.

7. Aronow WS (2011) Hypertension guidelines. Hypertension 58: 347-348.

8. Aronow WS, Banach M (2012) Ten most important things to learn from the ACCF/AHA 2011 expert consensus document on hypertension in the elderly Blood Press 21: 3-5.

9. Cooper-DeHoff RM, Gong Y, Handberg EM, Bavry AA, Denardo SJ, et al. (2010) Tight blood pressure control and cardiovascular outcomes among hypertensive patients with diabetes and coronary artery disease. JAMA 304: 61-68.

10. ACCORD Study Group, Cushman WC, Evans GW, Byington RP, Goff DC Jr, et al. (2010) Effects of intensive blood-pressure control in type 2 diabetes mellitus. N Engl J Med 362: 1575-1585.

11. Redon J, Mancia G, Sleight P, Schumacher H, Gao P, et al. (2012) Safety and efficacy of low blood pressures among patients with diabetes. Subgroup analyses from the ONTARGET (ONgoing Telmisartan Alone and in combination with Ramipril Global Endpoint Trial). J am Coll cardiol 59: 74-83.

12. UK Prospective Diabetes Study Group (1998) Tight blood pressure contro and risk of macrovascular and microvascular complications in type 2 diabetes: UKPDS38. UK Prospective Diabetes Study Group. BMJ 317: 703-713.

13. Hansson L, Zanchetti A, Carruthers SG, Dahlöf B, Elmfeldt D, et al. (1998) Effects of intense blood pressure lowering and low dose aspirin in patients with hypertension: principal results of the Hypertension Optimal Treatment (HOT) randomized trial. Lancet 351: 1755-1762.

14. Patel A, ADVANCE Collaborative Group, MacMahon S, Chalmers J, Neal B, et al. (2007) Effects of a fixed combination of perindopril and indapamide on macrovascular and microvascular outcomes in patients with type 2 diabetes mellitus (the ADVANCE trial): a randomised controlled trial. Lancet 370: 829-840. 